\title{
AGRICULTURA REPUBLICII MOLDOVA: PROBLEME ECONOMICE ȘI PERSPECTIVE
}

\author{
Albu I., Albu D. \\ Universitatea Tehnică a Moldovei, Chișinău, R. Moldova \\ ion.albu@fcgc.utm.md, albudoina1995@gmail.com \\ https://doi.org/10.53040/9789975347204.20
}

\begin{abstract}
The agricultural sector holds a significant position in the economy of the Republic of Moldova, which requires permanent studies of the problems created and finding solutions to solve them. A common problem in the agricultural sector is the risks caused by weather variations, pest attack, irregular rainfall affecting agricultural products. Thus, it is important to promote the option of covering possible losses by insuring risks in agriculture. Agricultural insurance is a way to encourage farmers to get good results and to promote their well-being. For many countries with a stable market economy, fiscal measures targeting agriculture remain largely unchanged, and for the Republic of Moldova, which is in the process of transitioning to a market economy, fiscal reforms continue.
\end{abstract}

Key words: agriculture, gross domestic product, income tax, insurance

\section{Introducere}

Pământul este cea mai mare bogătie pe care o are Republica Moldova, iar agricultura este considerată ramura primordială de activitate a întregii populații.

$\mathrm{Cu}$ toate acestea, actual, agricultura din Moldova este ineficientă, anul trecut sectorul a înregistrat o productivitate scăzută, investițiile în domeniu au fost mici iar costurile exagerate. 
Productivitatea sectorului este de 2-3 ori mai mică decât în Europa şi situaţia creată este comparabilă cu cea din Europa a anilor 70. Producătorii agricoli autohtoni au devenit necompetitivi pe piața externă şi chiar internă cu oferte pentru o gamă redusă de produse la prețuri mari și de calitate joasă, iar ritmul de majorare a importurilor de produse agroalimentare fiind în creștere.

Agricultura este expusă la riscuri naturale, precum: calamităţi naturale, fluctuații frecvente a temperaturii, atacul dăunătorilor, precipitațiile neregulate și umiditatea, eroziuni, alunecări de teren, etc., care afectează produsele agricole constituie o problemă comună. Însă pe lângă aceste pericole, producătorii agricoli se confruntă şi cu probleme de ordin economic și managerial cum ar fi: imposibilitatea comercializării producției, cauzate de reducerea volumelor de achiziții publice; procurarea produselor agricole de către fabricile de conserve la prețuri reduse; slaba dezvoltare a serviciilor de colectare pentru export; lipsa ofertelor avantajoase pentru depozitare; lipsa logisticii în transportul produselor agricole pentru industria alimentară şi pentru comercializarea pe piaţă etc.

Nivelul scăzut de competitivitate a produselor agricole autohtone şi lipsa de diversitate a produselor contribuie la cedarea producției locale în fața celei de import. Republica Moldova tinde a deveni un stat importator net de produse agroalimentare.

\section{Contribuția agriculturii în Produsul Intern Brut}

Reieșind din condițiile create volumul producției agricole va scădea în $2020 \mathrm{cu}$ aproximativ $11,9 \%$. În cazul unor condiții meteo favorabile se prognozează pentru anul următor o creștere de circa $13,3 \%$, iar ulterior creșterile se vor stabili în limita unui procent. Pentru toată perioada de prognoză, incertitudinea condițiilor climaterice rămâne a fi un factor de risc major. Totuşi, acest risc poate fi diminuat prin implementarea tehnologiilor performante și creșterea investițiilor în sector, tendințe înregistrate în ultima perioadă.

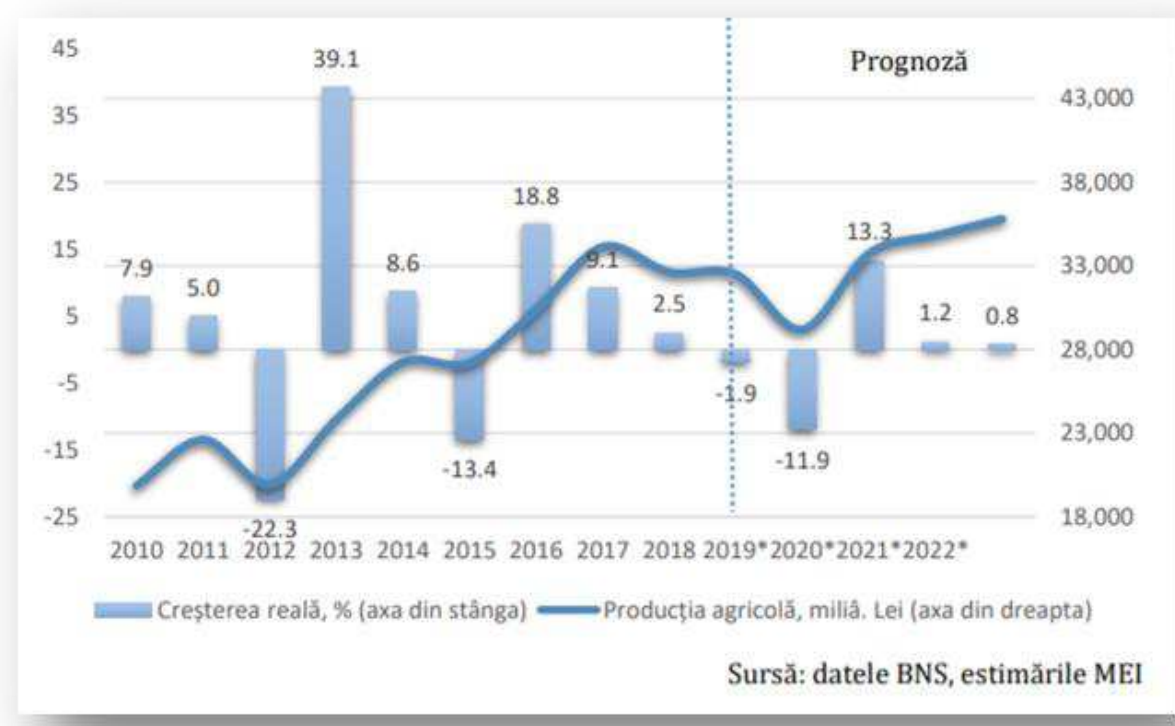

Figura 1. Prognoza producției agricole pentru perioada anilor 2020-2022 
Tabelul 1. Prognoza indicatorilor macroeconomici pentru anii 2020-2022 (coordonată cu Fondul Monetar International)

\begin{tabular}{|l|r|r|r|r|r|r|r|}
\hline \multirow{2}{*}{ Indicatori } & 2017 & 2018 & 2019 & 2020 & 2021 & 2022 \\
\cline { 2 - 7 } & \multicolumn{3}{|c|}{ Efectiv } & \multicolumn{3}{c|}{ Prognoze } \\
\hline Produsul intern brut nominal, mild. lei & 178,9 & 192,5 & 210,1 & 205,2 & 223,4 & 243,9 \\
\hline Exporturi, mil. USD & 2425 & 2706 & 2779 & 2421 & 2934 & 3225 \\
\hline \multicolumn{1}{|c|}{ Importuri, mil. USD } & 4831 & 5760 & 5842 & 5256 & 6269 & 6799 \\
\hline Soldul balanței comerciale, mil. USD & -2406 & -3054 & -3063 & -2835 & -3334 & -3574 \\
\hline Producția industrială, mild. lei & 52,7 & 56,2 & 58,4 & 57,7 & 62,0 & 65,8 \\
\hline Producția agricolă, mild. lei & 34,1 & 32,6 & 32,5 & 29,2 & 33,7 & 34,8 \\
\hline Ponderea producției agricole în PIB, \% & 19,06 & 16,94 & 15,47 & 14,23 & 15,09 & 14,27 \\
\hline
\end{tabular}

Sursa: Elaborat de autor în baza estimărilor Ministerului Agriculturii, Dezvoltării Regionale și Mediului

Analizând informaţia din tab. 1, constatăm că sectorului agricol pentru R. Moldova este important, în condiţiile în care agricultura, împreună cu silvicultura şi pescuitul, deține o cotă de circa 15\% în Produsul Intern Brut.

\section{Impozitul pe venit în agricultură}

Orice gen de activitate practicat este supus impozitării. Conform principiilor fiscale impozitarea urmează a fi echitabilă, astfel încât antreprenorii să poată plăti sumele calculate, să nu ajungă în situaţia când vor fi nevoiți a apela la credit pentru achitarea impozitelor.

Cotele generale de impozitare asupra veniturilor personale variază în funcție de țară, nivelul veniturilor și numărul de cote de impozitare marginale (fig. 2). De exemplu, printre țările cu rate de impozitare marginală scăzută se regăsesc: Republica Cehă, Ungaria și Elveția. Luxemburg, Mexic, Chile, Israelul și Austria au rate multiple, în timp ce Letonia și Estonia au o rată unică, indiferent de nivelul veniturilor. În mod similar, țările cu o rată de impozitare mai mare: Germania are doar două rate, iar Regatul Unit și Olanda au trei.

S-ar putea aștepta ca concesiunile fiscale agricole să fie asociate cu rate generale ridicate (și invers). De exemplu, Elveția nu oferă agricultorilor concesii fiscale, deoarece cotele generale de impozitare sunt foarte mici. În același timp, fermierii cehi beneficiază de concesii de impozitare pe venit, în ciuda ratelor scăzute de impozitare pe venit.

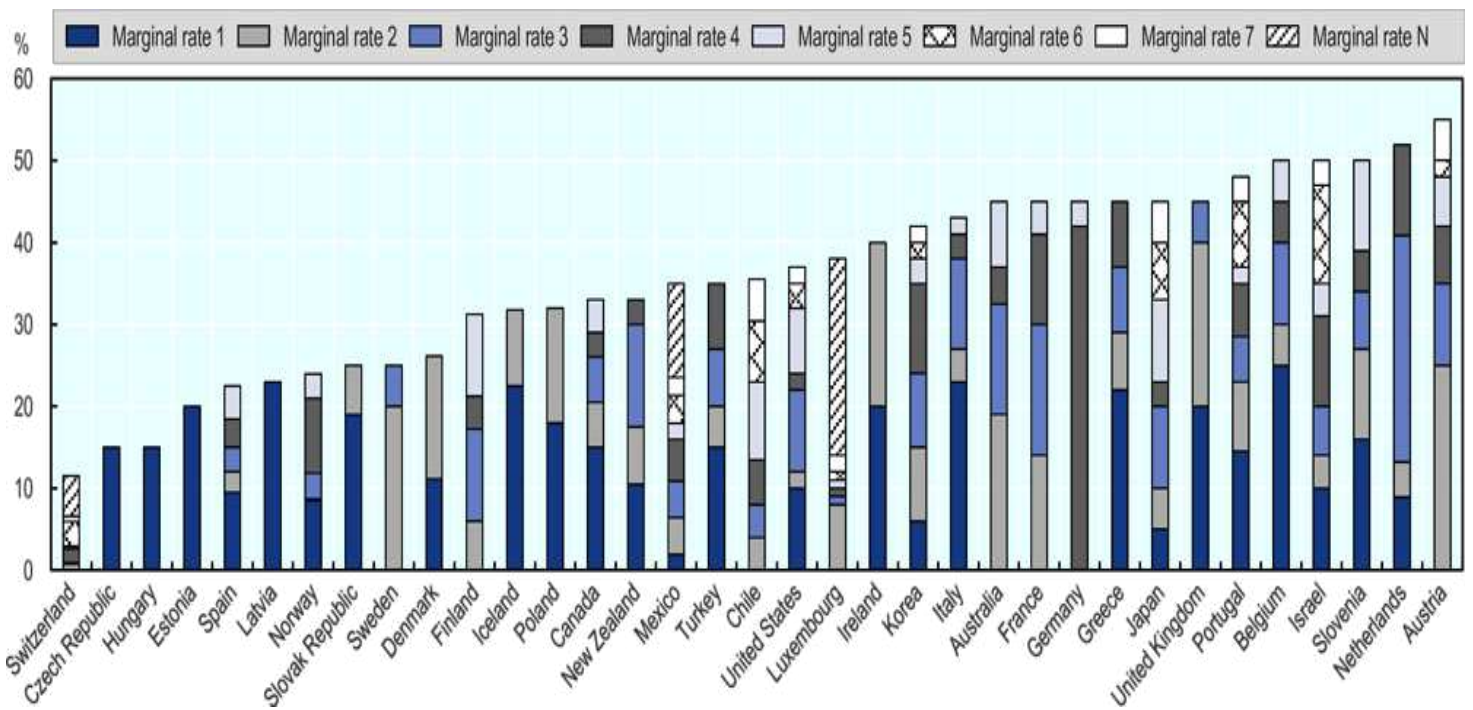

Figura 2. Ratele impozitului pe venitul personal în agricultură 
În Republica Moldova impozitul pe venit pentru gospodăriile țărănești (de fermier) este în mărime de $7 \%$ din venitul impozabil, iar pentru întreprinderi $12 \%$.

Este oare o povară pentru agricultori impozitul pe venit în comparație cu ratele practicate în alte state?

Majoritatea țărilor oferă tratament fiscal diferențiat pentru sectoarele agricole, practici bune pentru viitorul agricultorilor din Moldova.

Propunem a perfecționa următoarele direcții:

$\checkmark$ Tratament diferențiat în calculul și achitarea impozitului pe venit;

$\checkmark$ Contabilitate simplificată pentru sectorul agricol;

$\checkmark$ Scutiri de impozite pentru veniturile din activitățile tinerilor fermieri;

$\checkmark$ Acceptarea amortizării accelerate în scopuri fiscale;

$\checkmark$ Reduceri la impozitele funciare pentru a încuraja practicile agricole;

$\checkmark$ Stimulentele fiscale pentru dezvoltare, cercetare și inovare în sectorul agricol.

\section{Asigurarea în agricultură}

Asigurarea culturilor este o politică cuprinzătoare bazată pe randament menită să compenseze pierderile fermierilor care apar din cauza problemelor de producție. Acoperă pierderile de pre-însămânțare și post-recoltare din cauza ploilor abundente și a deficitului de precipitații. Aceste pierderi duc la reducerea randamentului culturilor, afectând astfel veniturile agricultorilor.

În anul 2019, asigurarea subvenționată a riscurilor în agricultură a fost desfășurată de şapte companii de asigurări, care au încheiat 116 contracte cu suma asigurată de 400 mil. lei, iar despăgubirile de asigurare achitate au însumat 4,60 mil. lei. Mijloacele alocate de stat pentru plata primelor de asigurare au constituit 5,66 mil. lei.

Conform Legii 243-XV din 08.07.2004 şi HG 455 din "21" iunie 2017, statul acordă asiguraților - persoanelor juridice $50 \%$ din prima de asigurare, sub formă de subvenții, la încheierea contractelor de asigurare a culturilor agricole, plantațiilor multianuale şi animalelor/păsărilor domestice.

Compania de asigurare acordă gratuit suportul necesar pentru a contracta o asigurare subvenționată la $50 \%$ din suma primelor de asigurare.

Asigurările în agricultură reprezintă un mecanism viabil de lungă durată şi practicarea acestuia ar permite diminuarea riscurilor. Însă nu este practicat pe scară largă în R.Moldova.

Motivele ratei scăzute de participare la asigurările agricole sunt următoarele:

$\checkmark$ producătorii agricoli nu înțeleg pe deplin asigurările;

$\checkmark$ pachete de asigurare neatractive;

$\checkmark$ insuficiența mijloacelor bănești;

$\checkmark$ nu au cunoştinţe şi educație financiară;

$\checkmark$ primele pentru asigurarea riscurilor sunt prea mari;

$\checkmark$ experiența negativă avută cu unii asigurători (pierderea încrederii);

$\checkmark$ nu sunt de acord cu evaluările pierderilor;

$\checkmark$ comportament de rea-credință din partea reprezentanților companiilor de asigurare;

$\checkmark$ refuzul sau achitarea cu întârziere a despăgubirilor;

$\checkmark$ birocrație excesivă şi numărul mare de documente necesare.

Pentru a exclude subiectivismul sau estimările greșite în procesul de calculare a sumei asigurate se recomandă axarea de recolta medie prognozată la hectar şi preţul anticipat de comercializare a acesteia, care nu poate depăși preţul maxim de comercializare obținut de către producătorul agricol în ultimii 5 ani, confirmat prin acte contabile, iar în cazul 
producătorilor care nu au o experiență de 5 ani, de utilizat datele Biroului Național de Statistică.

Oricum, companiile de asigurări urmează să-şi regândească strategiile de business în agricultură, să propună noi produse de asigurare şi să nu se bazeze doar pe subvențiile oferite de stat.

\section{Avantajele asigurării bunurilor agricole:}

1. Oferă sprijin financiar agricultorilor, acoperă pierderea recoltei și daunele cauzate de evenimente neprevăzute;

2. Subvenționarea primelor de asigurare în mărime de $50 \%$ pentru persoanele juridice care dețin culturi agricole, plantații multianuale, animale/păsări domestice;

3. Flexibilitate în selectarea riscurilor asigurate: poate fi luat în asigurare un singur risc sau câteva cumulativ, la un tarif atractiv;

4. Posibilitate de achitare în tranșe a primei de asigurare: plata primei de asigurare poate fi achitată în 2 rate a câte $50 \%$;

5. Liniște sufletească, deoarece nu trebuie să ia credite de la băncile comerciale la rate mai mari ale dobânzii pentru acoperirea pierderilor;

6. Asigurătorul va prelua povara financiară, achitând băncii soldul creditului restant şi va acorda Asiguratului despăgubirea în valoarea sumei de asigurare rămase după stingerea obligațiunilor debitoriale;

7. Economia țării se va consolida, deoarece agricultorii pot rambursa creditele cu despăgubirile primite de la asigurarea recoltei.

\section{Concluzii}

Agricultura în R.Moldova dispune de un potenţial natural, uman, dar mai puţin economic de dezvoltare, existând decalaje mari în înzestrarea tehnică, productivitatea muncii, utilizarea de Bio - îngrăşăminte, inovare în domeniu, cu toate acestea, prin politici coerente de modernizare, măsuri bine calculate şi eforturi comune ale agricultorilor, producătorilor şi exportatorilor cu susţinere din partea autorităţilor, se poate reabilita şi dezvolta agricultura şi contribui la dezvoltarea țârii şi a bunăstării poporului.

Investițiile reduse în echipamente mari și îngrășăminte - acest lucru se datorează faptului că pe piață activează multe ferme mici și instabile.

Practicarea agriculturii în mod profesionist - necesită investiţii de lungă durată şi în acest sens fac față numai companiile mari care dețin infrastructură pentru acest gen de activitate.

Scutire la impozitul pe venit pe prima plătită de agricultori pentru achiziționarea poliței de asigurare a riscurilor.

Subvenționarea în agricultură axată pe impozitele plătite - de acordat numai companiilor rentabile, care contribuie la dezvoltarea economiei țării.

Credite comerciale cu garanții din partea statului să se acorde numai companiilor agricole ce demonstrează o rentabilitate medie pe ultimii 5 ani dublă față de dobânda băncilor comerciale, celorlalți să se acorde credite cu garanții materiale cu asigurare obligatorie.

\section{Bibliografie}

1. Codul fiscal al RM. https://sfs.md/CodulfiscalalRM.aspx (accesat la 13.09.2020)

2. Legea Nr. 243, din 08-07-2004, privind asigurarea subvenționată a riscurilor de producție în agricultură. Publicat la 06.08.2004 în Monitorul Oficial Nr. 132-137 art. 704 https://www.legis.md/cautare/getResults?doc_id=27044\&lang=ro (accesat la 14.09.2020) 
3. Notă cu privire la prognoza principalilor indicatori macroeconomici pentru anii 20212023, https://mei.gov.md/sites/default/files/document/attachments/prognoza_macro-revizuitiulie-site.pdf (accesat la 13.09.2020)

4. Asigurarea culturilor: acoperire, revendicare și reînnoire, https://www.paisabazaar.com/rural-insurance/crop-insurance/ (accesat la 14.09.2020) 